\title{
Application of Neuro-Fuzzy Estimation for Rotor Flux in Speed Vector Control of Bearingless Induction Motor
}

\author{
José Soares Batista Lopes ${ }^{1}$, Luciano P. dos Santos ${ }^{1}$, José Á. de Paiva ${ }^{1}$, Valcí F. Victor ${ }^{2}$, André L. Maitelli ${ }^{3}$ and \\ Andres O. Salazar ${ }^{3}$ \\ 1. Institute of Education, Science and Technology of Rio Grande do Norte, RN 59200-000, Brazil \\ 2. Institute of Education, Science and Technology of Tocantis, TO 77.015-200, Brazil \\ 3. Department of Computer Engineering and Automation, Federal University of Rio Grande do Norte, Natal 59072-970, RN, Brazil
}

Received: September 16, 2014 / Accepted: November 10, 2014 / Published: February 28, 2015.

\begin{abstract}
The main requirement of a vector controller is knowing the magnitude and position of the rotating flow in the rotor. This feature permits to use either flow sensors or flow estimators. The solution chosen was the estimation of rotor flux with the hybrid neuro-fuzzy system. The motor characteristics are: $3.75 \mathrm{~kW}$ (5 HP), two pole-pair, operate at $60 \mathrm{~Hz}$ and air-gap length $0.2 \mathrm{~mm}$. The ANFIS (adaptive neuro-fuzzy inference system) was used to tune the membership functions in fuzzy system. The hybrid estimator aims at compensating possible parametric variations of the machine caused by agents, such as temperature or nucleus saturation. The simulated results have shown good performance.
\end{abstract}

Key words: Hybrid systems, rotor flux, estimation, speed control, ANFIS.

\section{Introduction}

In several industry sectors, for example, in the oil extraction field, the constant problems with maintenance, reliability, efficiency and lifetime issues in conventional electrical machines are leading to the use of BIMs (bearingless induction motors) [1,2].

For application of new technologies in the IM (induction motor), it is necessary to know the mathematical model to be able to incorporate almost all control techniques as: estimation and detection. Over the years, researches on control of induction motors have been focused on the improvement of control system for field-oriented or vector control, to solve the problems presented by the use of sensors attached to or installed near the rotor [3].

The flux information was used in IM control to obtain the synchronous angle and synchronous speed estimations, flux regulation and torque regulation. In

Corresponding author: José Soares Batista Lopes, professor, research fields: intelligent systems, educational robotics and automation. E-mail: jose.soares@ifrn.edu.br. this paper, we have solved the problem with assembling the flow sensors in the BIM. To replace the sensor, it is necessary to estimate the flux speed and the magnetization current simultaneously. Both parameters define the rotor flux position (after integrating flux speed) and the rotor flux magnitude using the ANFIS (adaptive neuro-fuzzy inference system). We have chosen a technique that uses the rotor flux vector as reference, requiring only the stator phase currents and mechanics speed according with Ref. [4].

ANFIS is a neural network which uses Sugeno-Fuzzy system [5]. Using a given input-output data set, ANFIS constructs a FIS (fuzzy inference system) whose membership function parameters are tuned using either a back propagation algorithm alone, or in combination with a least squares type of method. Ref. [6] proposed the development and implementation of an estimator based on ANFIS to senseless control speed of IM drives. This paper analyzes the performance of ANFIS for estimation of the motor's parameter in order to counterbalance the limitations of 
the conventional observer. Thus, this research is an improvement of Ref. [4] that worked with neural networks and continuation of the work of Ref. [1]. The results simulated in Matlab ${ }^{\circledR}$ have shown a good result to flux estimation.

\section{Conventional Estimator}

The flux estimation or conventional estimator has used the vector model of conventional induction machine [7]. The applied model can be described by the following Eqs. (1)-(5):

$$
\begin{gathered}
\mathrm{d}_{i m R}(t) / \mathrm{d} t=\left[i_{i m R}(t)-i_{m R}(t)\right] \mathrm{T}_{\mathrm{R}} \\
\mathrm{d} \rho(t) / \mathrm{d} t=n_{p} . \omega_{m e c}(t)+i_{s q}(t) /\left[\mathrm{T}_{\mathrm{R}} i_{m R}(t)\right] \\
m_{M}(t)=k i_{m R}(t) i_{s d}(t) \\
\mathrm{T}_{\mathrm{R}}=L_{R} / R_{R} \\
k=\frac{2}{3}(1-\sigma) L_{s}
\end{gathered}
$$

where, $i_{m R}$ is the magnetizing current, $i_{s d}$ and $i_{s q}$ are the Park currents, $\rho$ is the rotor flux position, $m_{M}$ is the electric torque, $\omega_{\text {mec }}$ is the mechanical rotor speed, $T_{R}$ is the rotor time constant, $L_{R}$ and $R_{R}$ are rotor inductances and rotor resistances, respectively, $L_{S}$ is the stator inductance and $\sigma$ is the scattering factor.

The rotor variables estimation performed using the rotor flux frame of reference, since it significantly simplifies the implementation of the digital system [4]. The parameters adopted in IM are listed in Table 1. It includes some laboratory measured test parameters as (per phase) equivalent inductances or resistances [1] to be used in simulation models.

Considering the IM with the rotor centralized working as the conventional motor. Then, the use of conventional vector model of induction machines in implementing the BIM, with divided windings, was only possible due to the similarity between both stator structures. These similarities are equivalent in both models, enabling the implementation of positioning, and radial velocity controllers [8].
Table 1 Equivalent circuit parameters of the IM.

\begin{tabular}{lll}
\hline Symbol & Parameter & Value \\
\hline$R_{1}$ & Stator resistance & $1.18 \Omega$ \\
$R_{2}$ & Rotor resistance & $1.42 \Omega$ \\
$J$ & Inertia moment & $0.00995 \mathrm{~kg} \cdot \mathrm{m}^{2}$ \\
$L s$ & Stator inductance & $6.56 \mathrm{mH}$ \\
$L_{r}$ & Rotor inductance & $6.56 \mathrm{mH}$ \\
$L_{m}$ & Magnetizing inductance & $0.14 \mathrm{H}$ \\
\hline
\end{tabular}

\section{Bearingless Motor with Divided Windings}

The induction machine stator used has divided windings, as shown in Fig. 1.

The rotor employed in the machine has shown a good performance in controlling radial position and speed control [4]. The currents applied to each half-winding are given by:

$$
\begin{aligned}
& i_{a 1}=i_{a}+\Delta i_{a 1} \\
& i_{a 2}=i_{a}-\Delta i_{a 2} \\
& i_{b 1}=i_{b}+\Delta i_{b 1} \\
& i_{b 2}=i_{b}-\Delta i_{b 2} \\
& i_{c 1}=i_{c}+\Delta i_{c 1} \\
& i_{c 1}=i_{c}-\Delta i_{c 1}
\end{aligned}
$$

Thus, the considerations below were adopted for the model of the induction machine following the model BIM:

- The BIM principle operating with the centralized rotor is equivalent to the conventional model of the IM [8];

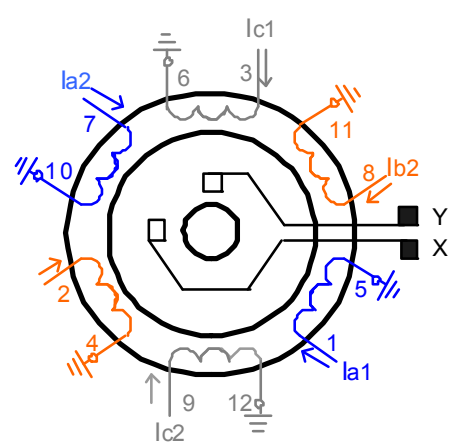

Fig. 1 Stator of an induction type BIM. 
- It was used the motor parameters, Table 1 , adopted in Ref. [1], in which the conventional induction machine operates as a BIM;

- According to Ref. [4], by neglecting the viscous friction of the bearings for the conventional machine model, it will allow to approximate to the BIM model;

- It was considered that the rotor operates centralized with the goal to reduce the complexity of the system implemented using the estimated ANFIS with balanced three-phase supply.

By adopting those criteria, the model of the IM will behave as a model of BIM. BIM is an integration of magnetic bearing with the function of a motor [9]. The electromagnetic torque of the BIM was based on Lorentz-Forces, as in the general IM [10].

\section{System Description}

Fig. 2 contains the block diagram of the BIM, current transformation blocks, PWM (pulse-width modulation) are command block, PID (proportional integral and derivative) blocks, power inverter blocks and other auxiliary circuit related. The referential rotor flux is estimated to implement the speed controller. The magnetizing current control was responsible for generating the current reference field [4]. Thus, torque control is responsible for generating the reference torque current. The orange block represents the ANFIS estimator.

\section{Hybrid System Neuro-Fuzzy: ANFIS}

ANFIS was introduced in Ref. [11]. ANFIS is a structure based on the model Takagi-Sugeno first-class.

According to Fig. 3, the structure of ANFIS consists of a five-layer feed forward network. The nodes in each layer have the same functionality:

Layer 1: every node $i$ in this layer is a square node with a node function as:

$$
O_{1, i}=\mu_{A i}\left(x_{1}\right), i=1,2 O_{2, i}=\mu_{B i}\left(x_{2}\right), i=1,2
$$

Layer 2: every node in this layer is a fixed node labeled as $\Pi$, whose output in the product of all incoming signals:

$$
O_{2, i}=w_{i}=\mu_{A i}\left(x_{1}\right) \mu_{B i}\left(x_{2}\right), i=1,2
$$

Layer 3: every node in this layer is a fixed node labeled as $\mathrm{N}$. The $i$ node calculates the ratio of the rule is firing strength to sum of all rules firing strengths:

$$
O_{3, i}=w_{i}=w_{i} /\left[w_{1}+w_{2}\right], i=1,2
$$

The output represents the weight of the decision rule.

Layer 4: the outputs of the neurons are calculated by the product of the rules consequences. Parameters in this layer are referred to as "consequent parameters".

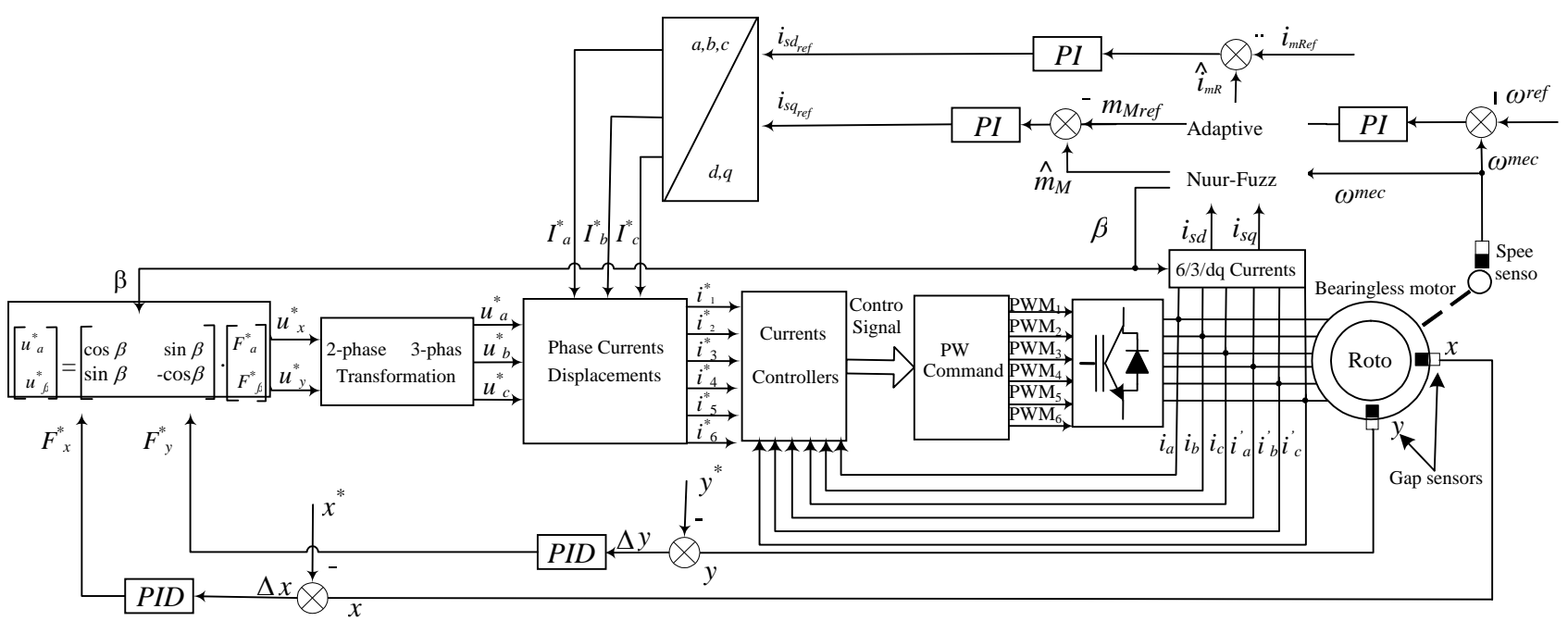

Fig. 2 Block diagram of system complete. 


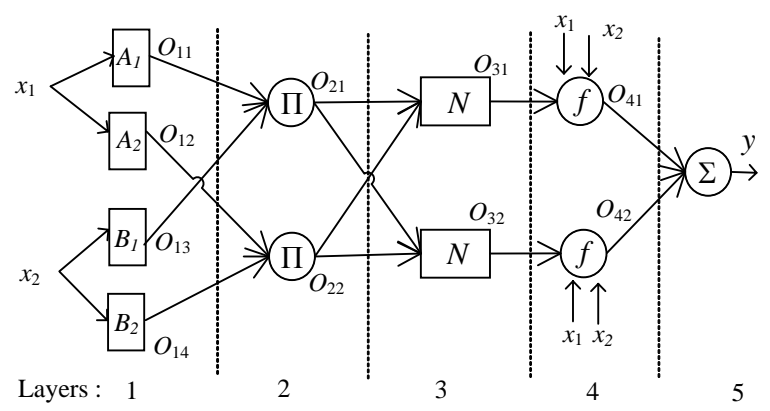

Fig. 3 Basic structure of ANFIS.

Layer 5: the single node in this layer is a fixed model labeled $\Sigma$ that computes the overall output as the sum of all incoming signals:

$$
O_{5, i}=\sum_{i} w_{i} f_{i}
$$

This structure can be trained by any learning mechanism used in the neural networks [12]. In this paper, back propagation learning algorithm was applied to training the ANFIS.

\section{Procedure of Tuning of ANFIS}

The software environment used for this simulation is Matlab $^{\circledR}$ R2010a. We applied the Euler discretization method with a step size $h$ equals 10e-5. The ANFIS training with data from the conventional model presented in Eqs. (7)-(10), using the nominal parameters of Table 1 , in the condition of the centralized rotor. The operation of ANFIS system at the Matlab ${ }^{\circledR}$ followed some steps: a set of membership function was chosen; load a set of input and output data to be used on the training of ANFIS; generate a FIS and validate the inference system.

The parameters of training were: hybrid optimization method, bell curve membership function, the linear output membership function and the number of epochs equals to the data in the Tables 2 and 3, obtained with estimator ANFIS. Inputs and outputs were normalized to help the process training data. The training period time was $40 \mathrm{~s}$.

The process of data training generation was based on the criteria in Ref. [4]. The training have used the
Table 2 Regarding training and testing of the ANFIS 1.

\begin{tabular}{lllll}
\hline $\begin{array}{l}\text { MF } \\
\text { shape }\end{array}$ & $\begin{array}{l}\text { MF per } \\
\text { entry }\end{array}$ & Epochs & Train.MSE & Test.MSE \\
\hline trimp & 2 & 300 & 0.000105349 & $3.465 \mathrm{e}-005$ \\
trapmf & 2 & 300 & $9.9718 \mathrm{e}-005$ & $2.794 \mathrm{e}-005$ \\
gbellmf & 3 & 500 & $7.7138 \mathrm{e}-005$ & $1.263 \mathrm{e}-005$ \\
gbellmf & 5 & 500 & $2.2373 \mathrm{e}-005$ & $1.870 \mathrm{e}-005$ \\
\hline
\end{tabular}

Table 3 Regarding training and testing of the ANFIS 2.

\begin{tabular}{lllll}
\hline $\begin{array}{l}\text { MF } \\
\text { shape }\end{array}$ & $\begin{array}{l}\text { MF per } \\
\text { entry }\end{array}$ & Epochs & Train.MSE & Test.MSE \\
\hline trimp & 2 & 300 & 0.0040629 & 0.0048989 \\
trapmf & 2 & 300 & 0.0039423 & 0.0048268 \\
gbellmf & 3 & 500 & 0.00170528 & 0.0024169 \\
gbellmf & 5 & 500 & 0.00119589 & 0.0016597 \\
\hline
\end{tabular}

offline mode in which we realized variations on the rotor time constant, electric torque and speed mechanical every 2 -second step on a random basis. The first structure designed estimates the magnetizing current and the second estimates the rotor flux (Fig. 4).

Each node in the structure of Fig. 3 represents an ANFIS layer of Fig. 4. Although we do not have basic knowledge of the parameter adjustments, the initial parameter settings were designed by ANFIS. This system manages to achieve quick adjustments without the need to know the induction machine underlying dynamics. The detailed parameters of the ANFIS 1 and 2 proposed are given in Table 4.
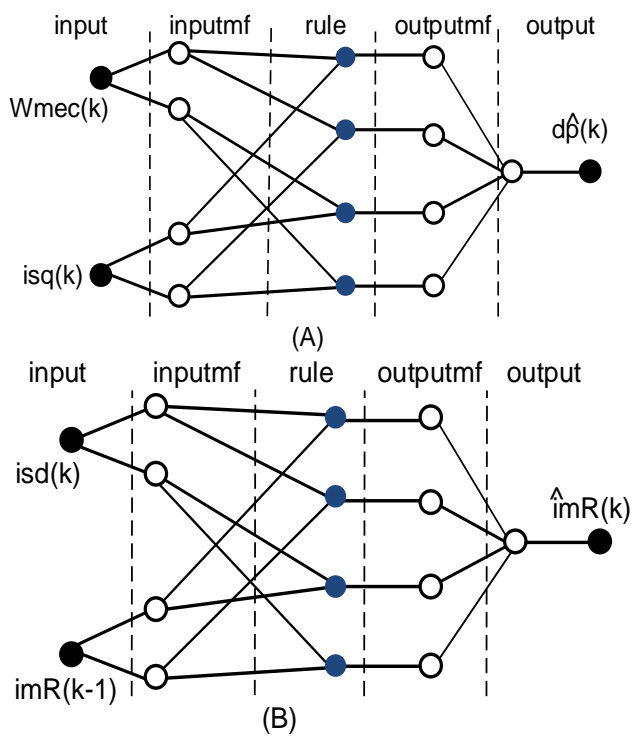

Fig. 4 ANFIS 1 (A): estimates magnetizing current and ANFIS 2 (B): estimates the flux rotor. 
Table 4 ANFIS parameters.

\begin{tabular}{ll}
\hline Number of nodes & 75 \\
\hline Number of linear and nonlinear parameters & 7,530 \\
Number of training data pairs & 40,201 \\
Number of checking data pairs & 4,021 \\
Number of fuzzy rules & 25 \\
\hline
\end{tabular}

\section{Results and Discussion}

To validate the performances of the proposed estimator ANFIS, we provided a sequence of simulations for different references. The simulation tests involve the following operating sequences: the motor is required to reach the reference value $\omega_{\text {mec }}=$ $1,800 \mathrm{rpm}$ in the time interval $0-10 \mathrm{~s}$ and $\omega_{\text {mec }}=1,500$ rpm for $0-20 \mathrm{~s}$.

The controller gains have been chosen as follows: $K_{\text {pwec }}=6$ (proportional mechanical rotor speed gain), $K_{\text {iwec }}=60$ (integrative mechanical rotor speed gain), $K_{p m M}=1$ (proportional electric torque gain), $K_{i m M}=$ 100 (integrative electric torque gain), and $K_{\text {pimR }}=2$ (proportional magnetizing current gain), $K_{\text {iim }}=50$ (integrative magnetizing current gain) in order to obtain fast and precise response in speed and flux tracking. The simulations run in the range of 0-20 s. Fig. 6 shows the comparative analysis of the results between the mechanical speed conventional model and the one estimated by ANFIS.

Fig. 6 has a zoomed view for better analyses. It was used a load variation $0.4 \mathrm{~N} \cdot \mathrm{m}$ at the time of $6 \mathrm{~s}$ with reference speed of $1,800 \mathrm{rpm}$. Fig. 7 shows the performance of PI control correspondent to the signal error.

Fig. 8 shows comparative results among the motor torques (Anfis and Conventional). Fig. 9 shows the error signal behavior of the torque control.

Figs. 10 and 11 show the current signal behavior $i_{s q}(t), i_{s d}(t)$ in Eqs. (2) and (3): the $i_{s d}(t)$ and $i_{s q}(t)$ currents tend to continuous and constant values, and the field current tends to the maximum amplitude of the phase currents.

Fig. 12 shows the angular speed of the rotor flux.

Fig. 13 shows the angular position in a zoom range from 0 to $0.1 \mathrm{~s}$. We observe this result timing of both $\rho(t)$ for the estimators.

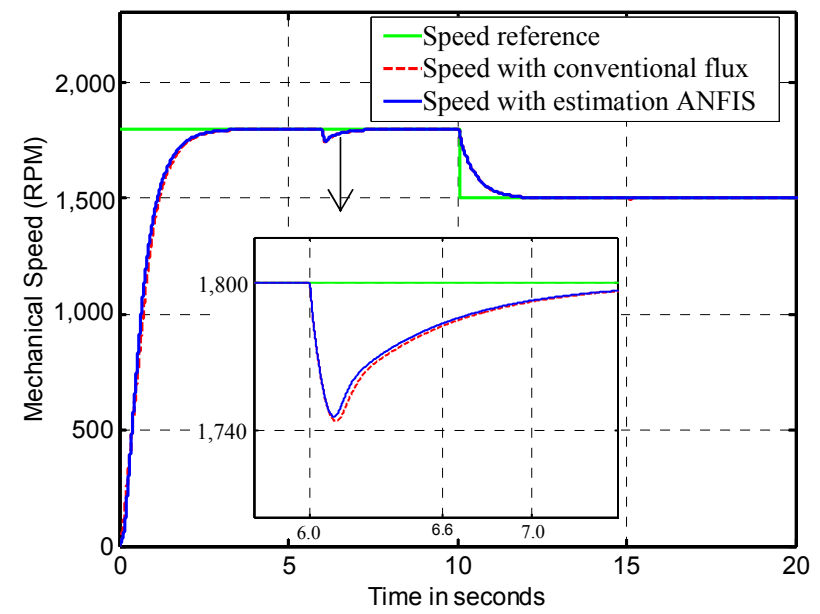

Fig. 6 Comparative results between mechanical speeds.

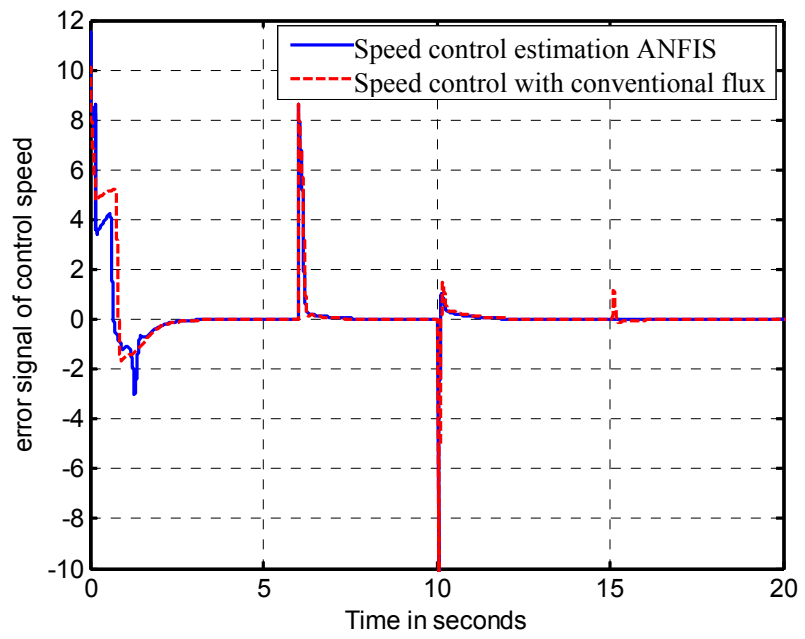

Fig. 7 Error signal of control speed.

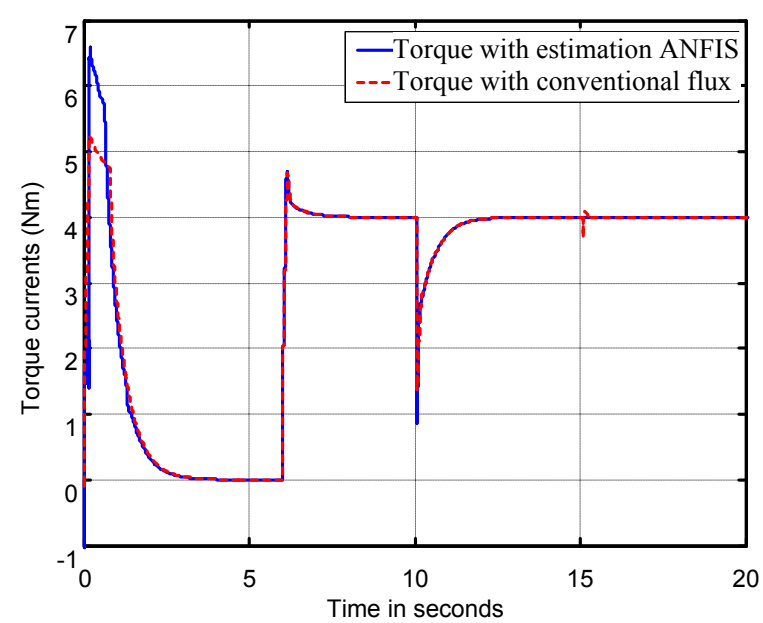

Fig. 8 Result of torque operating with load $0.4 \mathrm{~N} \cdot \mathrm{m}$. 


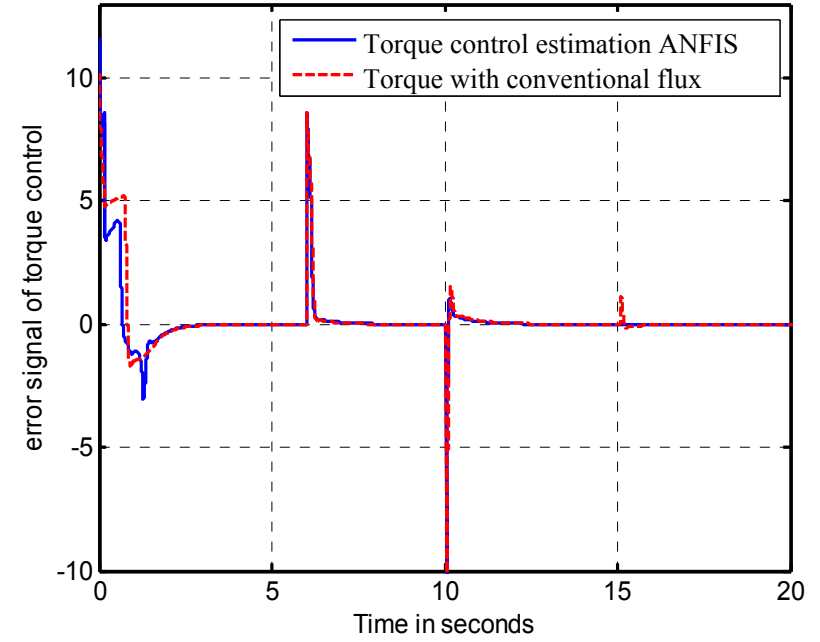

Fig. 9 Error signal of torque control.

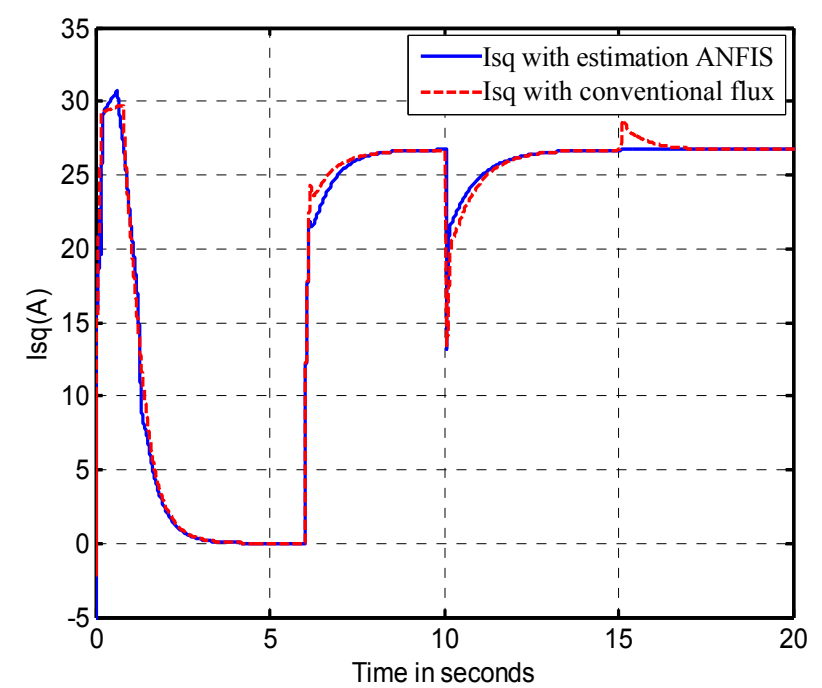

Fig. 10 Current signal behavior $i_{s q}(k)$.

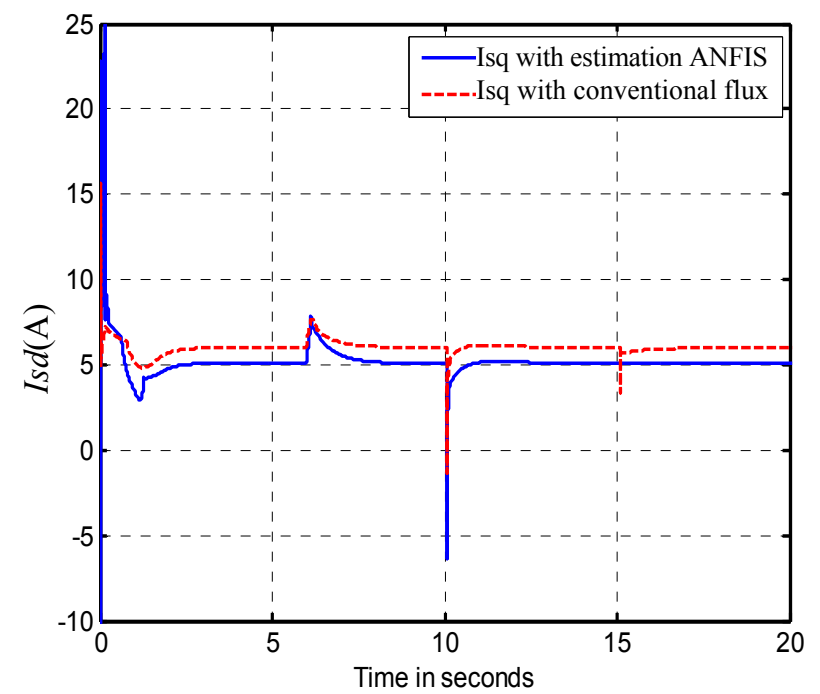

Fig. 11 Current signal behavior $i_{s d}(t)$.

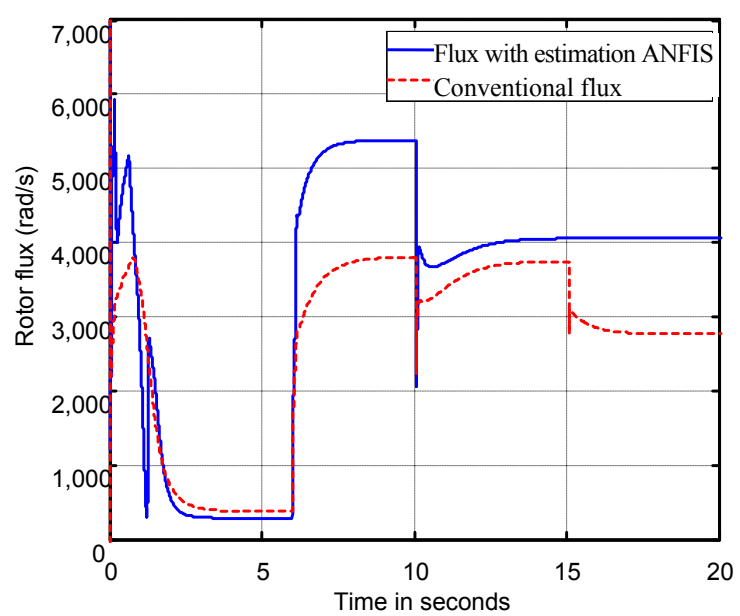

Fig. 12 Comparative results between the rotor fluxes.

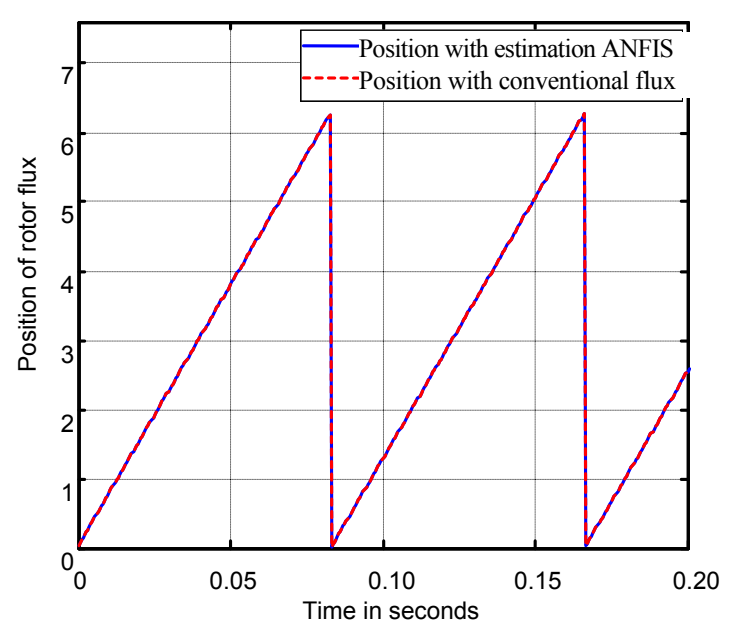

Fig. 13 Results comparatives between the position of rotor flux.

From these simulations, we can infer that the ANFIS estimator had good performance. We can observe, at the 15 -second instant, there was a small change to all simulations. Thus, all motor's parameters are time varying, in particular, the rotor time constant which is extremely affected by the heating effect [7]. In this case study, the $T_{R}$ parameter changed its value at $40 \%$ of its value. Then, ANFIS estimator did not suffer parametric variations. ANFIS exhibits better results due to its learning capability.

\section{Conclusions}

This paper shows the implementation of an inference mechanism system-neuro-fuzzy which allows the 
representation of the knowledge structuralized in rules. The validity of the proposed ANFIS estimator was confirmed through the simulation results. We investigated the ANFIS estimator in a closed loop system with three controllers: speed control, torque control and the magnetizing current control. Results demonstrated the effectiveness of neuro-fuzzy estimator. ANFIS showed itself robust to variations in rotor time, which is a parameter that disturbs the system. Finally, the ANFIS estimator was incorporated in the studied bearingless motor to estimator flux rotor and of magnetizing current. Forthcoming researches will investigate estimator ANFIS in an experimental prototype in laboratory.

\section{References}

[1] Victor, V. F., Quintaes, F. O., Lopes, J. S. B., and Junior, L. D. S. 2012. "Analysis and Study of a Bearingless AC Motor Type Divided Winding, Based on a Conventional Squirrel Cage Induction Motor." IEEE Transactions on Magnetics 48 (11): 3571-4.

[2] Sun, X., Chen, L., Yang, A., and Zhu, H. 2013. "Speed-Sensorless Vector Control of a Bearingless Induction Motor with Artificial Neural Network Inverse Speed Observer." IEEE/ASME Transactions on Mechatronics 18 (4): 135-66.

[3] Lopes, J. S. B., Junior, L. S, Paiva, J. Á., Salazar, A.O, Maitelli, A. L. 2013. "Adaptive Neuro-Fuzzy Inference System for Estimation of Rotor Flux of a Bearingless Induction Motor applied to Speed Control." Presented at the 1st Brazilian Workshop on Magnetic Bearings, Brazil.
[4] Victor, V.F., de Paiva, J.A., Salazar, A.O., Maitelli, A.L. 2009. "Performance Analysis of a Neural Flux Observer for a Bearingless Induction Machine with Divided Windings." In Power Electronics Conference, COBEP 09. Brazilian 498-504.

[5] Hou, Z. X., and Li, H. Q. 2006. "Nonlinear System Identification Based on Adaptive Neural Fuzzy Inference System." In Proceedings of the International Conference on Communications, Circuits and System, 2067-9.

[6] Lima, F., Kaiser, W., Nunes da Silva, I., and Oliveira, A. A. 2012. "Speed Neuro-Fuzzy Estimator Applied to Sensorless Induction Motor Control." IEEE Latin America Transactions (Revista IEEE America Latina) 10 (5): 2065-73.

[7] Leonhard, W. 2001. Control of Electrical Drives. 3rd ed. Berlin Heidelberg New York, Germany: Springer-Verlag.

[8] Ferreira, J. M. S., Zucca, M., Salazar, A. O., and Donadio, L. 2005. "Analyses of Bearingless Machine with Divide Windings." IEEE Transactions on Magnetics 41 (10) 3931-3.

[9] Liu, X., Zhu, B., Zheng J., and Wang, Z. 2011. "Air-Gap-Flux Oriented Optimized Control of Bearingless Induction Motor." In Proceedings of the 2011 30th Chinese Control Conference, 3549-53.

[10] Chen, H., Zhang, S., and Zhang, R. 2012. "Control of Rotor Radial Displacement for Bearingless Induction Motors." In Proceedings of the 7th IEEE Conference on Industrial Electronics and Applications (ICIEA), 1084-9.

[11] Jang, J. S. R. 1993. “ANFIS: Adaptive-Network-Based Fuzzy Inference System.” IEEE Transactions on Systems, Man and Cybernetics 23 (3): 665-85.

[12] Jang, T. S. R., Sun, C. T., and Mizutani, E. 1997. Neuro-Fuzzy and Soft Computing: A Computational Approach to Learning and Machine Intelligence. New Jersey: Prentice Hall. 